\title{
Storage Life Extension of Plum Fruit with Different Colored Packaging and Storage Temperatures
}

\author{
Muhammad Saeed Khan ${ }^{1}$, Alam Zeb ${ }^{1}$, Kamran Rahatullah ${ }^{1}$, Ihsanullah ${ }^{2}$, \\ Nazeer Ahmed ${ }^{3}$ and Saeed Ahmed ${ }^{4}$ \\ ${ }^{1}$ Department of food science and technology, The University of Agriculture, Peshawar-Pakistan \\ ${ }^{2}$ Nuclear Institute for Food and Agriculture, Tarnab-Peshawar \\ ${ }^{3}$ Department of Entomology, The University of Agriculture, Peshawar-Pakistan, \\ ${ }^{4}$ Department of Horticulture, The University of Agriculture, Peshawar-Pakistan
}

\begin{abstract}
A$ research was conducted to explore the effect of yellow, white and transparent polyethylene packaging on storage life extension of plum fruit stored at ambient temperature $\left(25 \pm^{\circ} \mathrm{C}\right)$ and refrigeration temperature $\left(1-4^{\circ} \mathrm{C}\right)$. Experiment was designed with simple randomized complete block design. The fruits were washed with tap water and surface dried under a fan. The fruits were divided into six polyethylene bags of different colors and the samples were numbered as $T_{0}, Y R, W R, T R, Y F, W F$ and $T F . Y R, W R$ and TR were stored at room temperature in yellow, white and transparent polyethylene packaging respectively. YF, WF and TF were stored at refrigerated temperature in yellow, white and transparent polyethylene packaging respectively. In our research study significant effect of polyethylene packaging and storage intervals was observed on most of the parameters. Samples were analyzed for its firmness, acidity, total soluble solids, weight loss, decay index and ascorbic acid. Highest mean values of weight loss (5.79), decay index (22.11), total soluble solids (9.92 ${ }^{\circ}$ Brix) and acidity (0.78) were found in sample $T_{0}$ while lowest mean values of weight loss (1.64), decay index (4.73), total soluble solids $\left(8.34^{\circ}\right.$ Brix) and acidity (0.65) were found in TF. Maximum ascorbic acid $(5.95 \mathrm{mg} / 100 \mathrm{~g})$ content was determined in YR while minimum ascorbic acid $(5.05 \mathrm{mg} / 100 \mathrm{~g})$ was recorded in TF. Firmness $(3.50 \mathrm{~kg})$ of the sample was highest in TF and lowest in YR. Samples were also studied for their sensory characteristics such as texture, flavor, color and overall acceptability. TF obtained maximum mean score of judges for color (6.92), flavor (6.37), texture (6.37) and overall acceptability (7.03) while minimum score rate was obtained by sample $T_{0}$. Treatment $T F$ (transparent colored packaging at refrigerated temperature) retained maximum quality attributes and also got maximum score for organoleptic evaluation. Statistical analysis showed that treatments and storage intervals had a significant $(P<0.05)$ effect on physico-chemical, characteristics and sensory analysis of plum fruit.
\end{abstract}

Keyword: Plum fruit, Colored Packaging, Storage intervals and temperatures Corresponding Author: Muhammad Saeed Khan

\section{Introduction}

Plum (Prunus domestica) belongs to the group of deciduous fruits commonly known as stone or drupe fruit. It is a true fruit and is characterized by having a distinct three layered peri-carp- an exo-carp, meso-carp and a stony endo-carp, which encloses the seed. It belongs to the genus prunus, sub genus Pronupora (plum and apricot) to the family Rosaceae (Saima, 2001).

Unlike most food products, fresh fruit and vegetables continue to 'breathe' or respire after they have been harvested. This process consumes oxygen and produces carbon dioxide and water vapors. The key to keeping these packaged products fresh for as long as possible is to reduce the respiration rate without harming the quality of the product, its taste, texture and appearance. In general, the rate of respiration can be reduced by keeping the temperature low, having lower levels of oxygen in the packaging atmosphere and increased levels of carbon dioxide. Packaging is a mean of providing a correct environmental condition for food. The method of food preservation is much more depending upon the packaging materials. Deterioration is a response to the external circumstances and much of the packaging, which remains in direct contact with food, delay the process of deterioration for the required time. Although chemical preservatives act upon controlling spoilage, but packaging provides support for chemical preservatives in addressing the issue of micro organism. Packaging also lowers the ingress of moisture, oxygen, or foreign odors. Packaging, obviously play a vital role in keeping the food clean and in hygienic condition (Hussain, 1986).

Modified atmosphere packaging (MAP) utilizes polymeric films with selective permeability for $\mathrm{O}_{2}$, $\mathrm{CO}_{2}$, and $\mathrm{H}_{2} \mathrm{O}$ vapor to create an MA around the packaged product due to the respiration of the product and the selective permeability of the packaging material (Guevara et al. 2003). 
Modified atmosphere packaging (MAP) is most commonly used for highly perishable commodities and effectively retards deterioration of fresh fruits and vegetables. MAP can prolong the shelf life of mushrooms Pleurotus nebrodensis to 90 aging. Days, inhibit the respiration and weight loss, and retard soluble sugars, titratable acidity and anthocyanin decrease of strawberries (Zhang et al. 2003). MAP significantly inhibits the lignification and delay of the ripeness of bamboo shoots. MAP using $0.03 \mathrm{~mm}$ Polyethylene film could inhibit weight loss and decrease total soluble solids (TSS), firmness of fruits and keep an acceptable appearance of mini tomatoes compared with control fruit.

The aim is to achieve a state known as equilibrium to produce a so-called equilibrium modified atmosphere, or EMA. Here, oxygen and carbon dioxide can pass between the inside and outside of the package in such a way that as oxygen is consumed within the pack it is replaced by oxygen from outside, and similarly a constant level of carbon dioxide is maintained. Another advantage of a modified atmosphere is that it reduces the natural production by the fruit or vegetable of a gas called ethylene, which speeds up the ripening process.

In Pakistan the post harvest losses are estimated to that of the total one third produce. The present study is to extend the shelf life of plum fruit by different colored polyethylene packaging. Plum fruit will be stored at ambient as will as at refrigerated temperature and will be studied for physical, chemical and organoleptic at four days intervals.

\section{Materials And Methods}

The present research work was conducted at Food Science Division of the Nuclear Institute for Food and Agriculture (NIFA) Tarnab, Peshawar, Pakistan.Plum fruits (not fully matured) were obtained from the orchard of NIFA in wooden crates lined with soft paper. Diseased and discolored skin fruits were discarded. Fresh plum fruits (not fully matured) with uniform size and color were selected for this experiment. The fruits were properly washed with tape water to remove dust and other undesirable materials attached with fruits. The fruits were divided into six lots (YR, WR, TR, YF, WF and TF). $T_{0}$ is control stored at room temperature, while YR, WR and TR were stored at room temperature in yellow, white and transparent polyethylene plastic bags. Similarly YF, WF and TF were stored at refrigerated temperature in yellow, white and transparent polyethylene plastic bags respectively. YR, WR and TR were stored at room temperature (wooden cup board) while YF, WF and TF were stored at refrigerated temperature (refrigerator). YR, WR and TR were placed in corrugated cub board and placed in controlled condition at $25 \pm^{\circ} \mathrm{C}$ to store them at uniform temperature according to the method described by Ahmed et al. (2007). The analyses were carried out initially and after four days interval i.e. 0 day 4, day 8 up to 32 days until the fruits were spoiled. Plum fruits were obtained from local plum (Fazl e Manani) orchard and were sorted. Fruits were then packed with different colors polyethylene packages according to the following planning. After packing fruit were kept at ambient and refrigerated temperatures.

\section{Proposed plan of study \\ $\mathrm{T}_{0} \quad=\quad$ Control \\ YR $\quad=\quad$ Yellow polyethylene plastic bag at room temperature \\ $\mathrm{WR}=\quad$ White polyethylene plastic bag at room temperature \\ TR $=\quad$ Transparent polyethylene plastic bag at room temperature \\ $\mathrm{YF}=\quad$ Yellow polyethylene plastic bag at refrigerated temperature \\ $\mathrm{WF}=\quad$ White polyethylene plastic bag at refrigerated temperature \\ $\mathrm{TF}=$ Transparent polyethylene plastic bag at refrigerated temperature}

\section{Quality Parameters to be studied}

Weight Loss

Weight loss of the fruits already separated from each treatment was determined as described by Wang et al. (2005). Fruits were weighed after every four days and the percent weight loss was calculated by using the following formula:

Weight loss $(\%)=$

$$
\frac{\mathrm{W}_{1}-\mathrm{W}_{2}}{\mathrm{~W}_{1}} \times 100
$$

Where:

$\mathrm{W}_{1}=$ Initial weight

$\mathrm{W}_{2}=$ Final weight

\section{Ascorbic Acid}

Ascorbic acid content $(\mathrm{mg} / 100 \mathrm{~g})$ of the samples was determined by the titramitric method as described in AOAC (2000). 
Decay index

The decay was assessed by measuring the extent of decayed area on each fruit, and was determined as: 0 , no decay; 1 , less than $1 / 4$ decay; $2,1 / 4-1 / 2$ decay; $3,1 / 2-3 / 4$ decay. Decay index of the samples was determined as described by Wang et al. (2005).

Total Soluble Solids

Firmness

Total soluble solids (TSS) were determined with digital refractometer according to (AOAC, 2000).

Firmness of the samples was determined by using recommended method of AOAC (2000). For this purpose penetrometer was used.

Acidity

Titratable acidity (\%) of the samples was determined by using recommended method of AOAC (2000), by titrating the sample against standard alkali solution.

\section{Sensory Evaluation}

Sensory evaluation of the fruits was carried out using a nine-point hedonic scale. The whole as well as cut fruit was presented to the judges for evaluation of appearance, odor and taste (Larmond 1977).

Statistical Model Torrie 1997).

The experiment was laid out in RCBD. The means were compared by applying LSD test (Steel and

\section{Weight loss}

\section{Results And Discussion}

The mean values of weight loss were recorded as 1.64 to 5.79 showing the maximum value at storage intervals for 32 days of the samples (5.79) was recorded for the sample $\mathrm{T}_{0}$ and the minimum mean value at storage intervals for the samples TF was recorded as (1.64) during 32 days of storage period. The percent increase was maximum (9.74) in the sample YR and was minimum (4.75) in the sample TF. An increase in the mean values of weight loss was seeing during the storage intervals of plum fruit in 32 days show in (Fig. 1).

The statistical analysis showed that temperature and storage intervals of treatments had a significant $(\mathrm{P}<0.05)$ effect on weight loss content of plum fruit during storage intervals. Weight loss is an important index of post harvest storage life in the fresh products. It is mainly attributing to the loss of water during metabolic processes like respiration. Moisture loss and gaseous exchange from the fruit is usually controlled by the epidermal layers provided with guard cells and stomata. A coating helps to reduce this further because it form a film on the top of the skin acting as an additional barrier to the moisture loss as been reported by Togrul And Arslan (2004). Weight loss was calculated according to the weights of each package before and after storage, and expressed as a percentage of the initial weight of mushrooms (Xiao and Zhang, 2003).

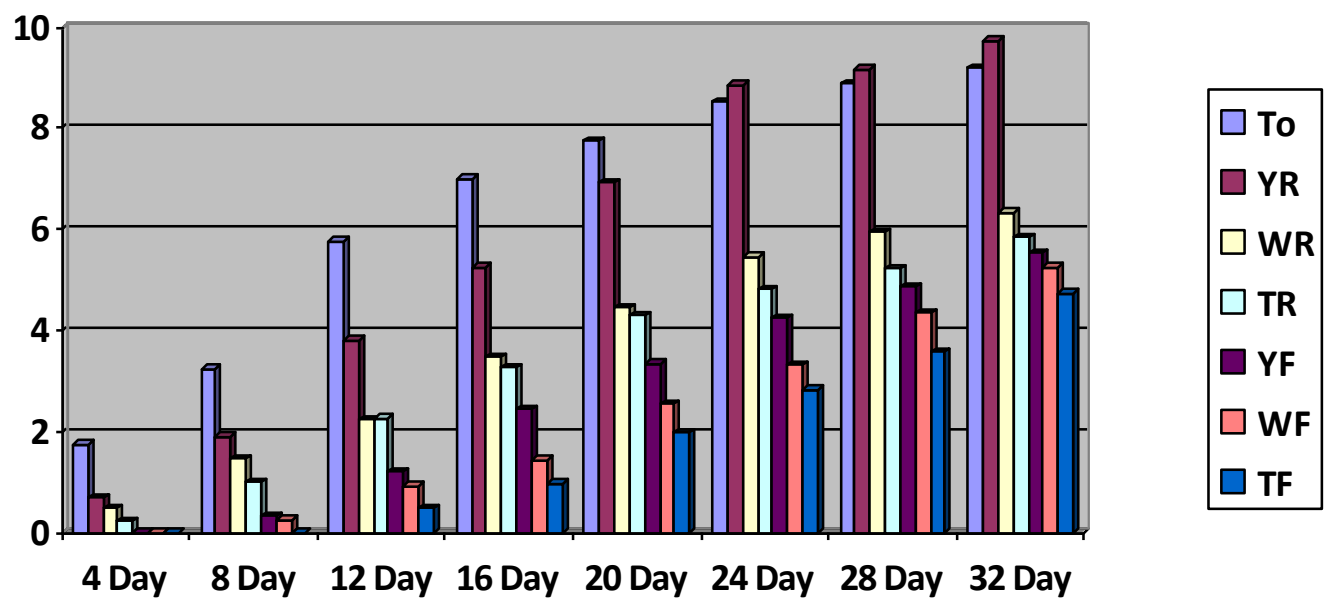

Fig. 1.Effect of different colored polyethylene packaging on weight loss (\%) of plum fruit stored at ambient and refrigerated temperatures.

\section{Ascorbic Acid}

The mean values of ascorbic acid were recorded from 5.05 to 5.91 showing the maximum mean value (5.97) was recorded for the sample YR and minimum mean value (5.05) was recorded for the sample TF. The percent decrease was maximum (44.66) in the sample TF and was minimum (33.23) in the sample TR. A decrease in the mean values of ascorbic acid was seeing during the storage intervals of plum fruit in 32 days 
shown in (Fig. 2). The statistical analysis showed that temperature and storage intervals of treatments had a significant $(\mathrm{P}<0.05)$ effect on ascorbic acid content of plum fruit during storage intervals. This decreasing of ascorbic acid during storage might be due to the presence of $\mathrm{O}_{2}$ which resulted in the conversion of ascorbic acid into dehydroascorbic acid. The presence of oxygen and high rate of respiration accelerates oxidation process in fruits. These results were in line with the finding of Sumnu and Bayindirli (1995).

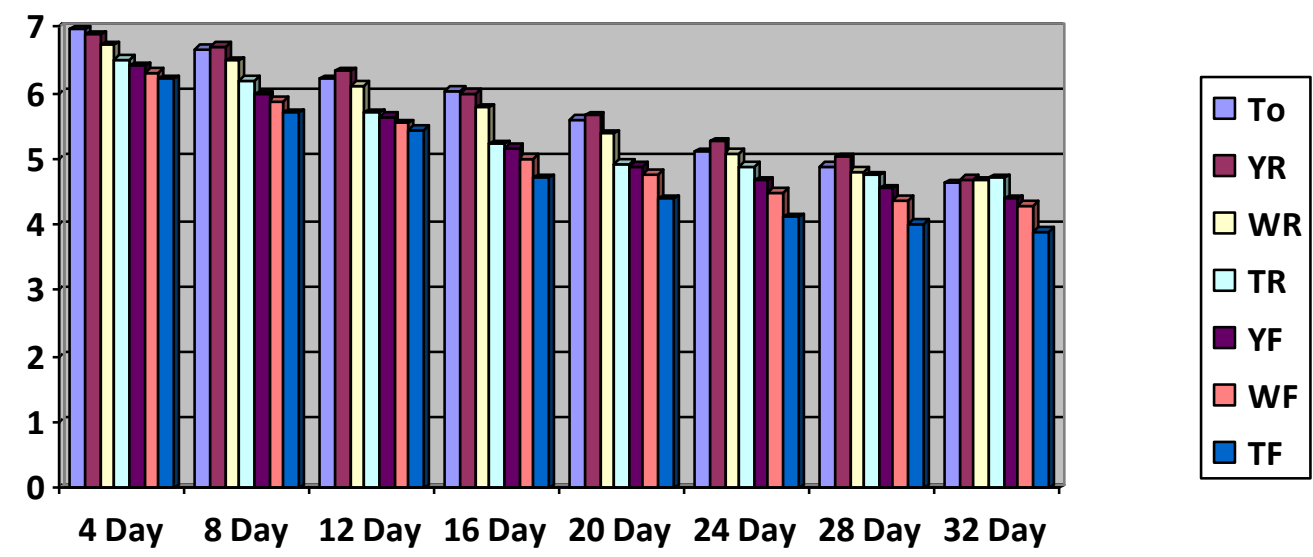

Fig. 2. Effect of different colored polyethylene packaging on ascorbic acid (mg/100g) of plum fruit stored at ambient and refrigerated temperatures.

\section{Decay Index \%}

The mean values of decay index were observed from 4.73 to 22.10 at storage intervals showing the maximum mean value (22.1) at storage intervals for 32 days for the samples $\mathrm{T}_{0}$ was recorded and the minimum mean value at storage intervals for the samples TF was recorded as (4.73) during 32 days of storage period. The percent increase was maximum (53.78) in the sample $\mathrm{T}_{0}$ and was minimum (16.58) in the sample $\mathrm{TF}$. An increase in the mean values of decay index was seeing during the storage intervals of plum fruit in 32 days show in (Fig. 3). The statistical analysis showed that temperature and storage intervals of treatments had a significant $(\mathrm{P}<0.05)$ effect on decay index content of plum fruit during storage intervals. Decay of citrus fruits after harvest of any given season depends on a number of factors over which the grower has little or no control. These includes variety, age of fruits, climate, time of bloom, local weather condition prior to harvest, abundance of inoculums of fungi causing decay, and many others. However, he does have some control over other factor which also greatly affect the shelf life of fruit; these include maturity of fruit, proper care and timing in harvesting, handling, processing, shipping and storage (Smoot And Melvin, 1967).

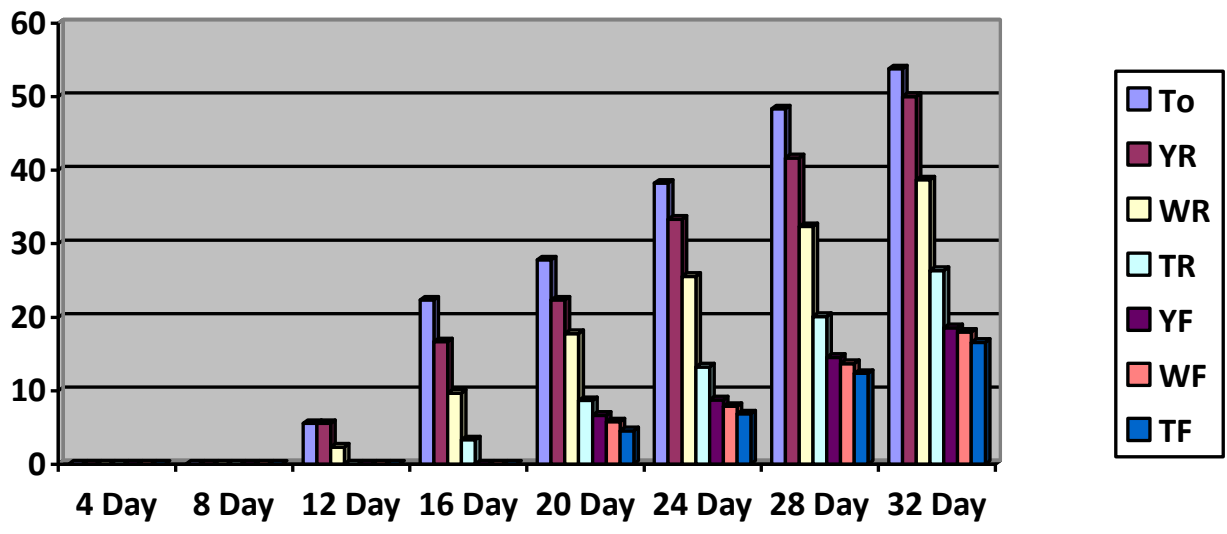

Fig. 3. Effect of different colored polyethylene packaging on decay index (\%) of plum fruit stored at ambient and refrigerated temperatures. 


\section{Total Soluble Solids}

The mean values of weight loss were observed from 8.34 to 9.92 at storage intervals showing the maximum mean value (9.92) at storage intervals for 32 days for the samples $T_{0}$ was recorded while the minimum mean value at storage intervals for the samples TF was recorded as (8.34) during 32 days of storage period. The percent increase was maximum (33.33) in the sample YR and was minimum (10.11) in the sample TF. An increase in the mean values of total soluble solids was seeing during the storage intervals of plum fruit in 32 days shown in (Fig. 4). The statistical analysis showed that temperature and storage intervals of treatments had a significant $(\mathrm{P}<0.05)$ effect on total soluble solids content of plum fruit during storage intervals. Change in total soluble solids (TSS) in the present study was might be due to the hydrolytic conversion of polysaccharide into soluble sugar as is the case in many climatric fruits during the ripening process. In the initial stages of storage, rate of conversion of insoluble polysaccharides was faster then the rate of fermentation of mono disaccharides into organic acids. Therefore, this resulted in an increase in total soluble solids (TSS) of the fruits. In the later stages of storage the rate of conversion of soluble mono and disaccharides into organic acid was faster than the conversion of insoluble mono and disaccharides into organic acids and thus resulted in increased total soluble solids (TSS) in the fruits. This increasing trend in total soluble solids (TSS) might be attributed to the microbial activity. The results are in line with the findings of Manzano et al. (1997) and Sarkar et al. (1997).

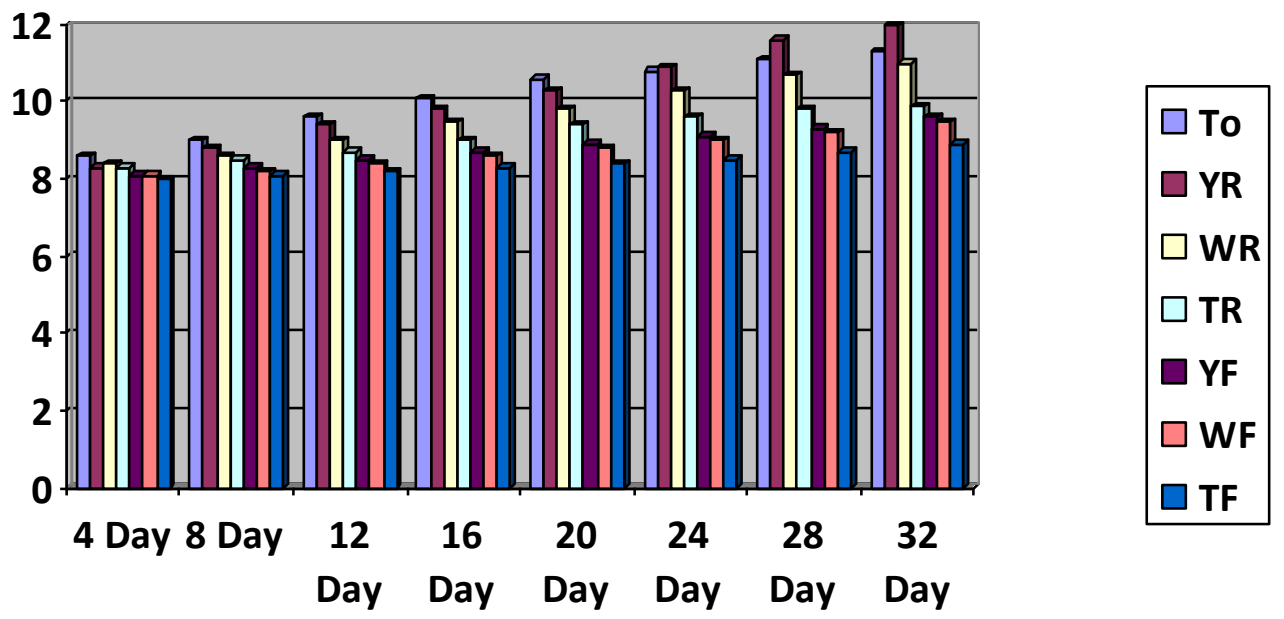

Fig. 4. Effect of different colored polyethylene packaging on TSS ( ${ }^{0}$ Brix) of plum fruit stored at ambient and refrigerated temperatures.

Firmness

The mean values of firmness were recorded from 3.38 to $3.5 \mathrm{~kg}$ showing the maximum mean value (3.5) was recorded for the sample TF and minimum mean value (3.34) was recorded for the sample YR. The percent decrease was maximum (57.44) in the sample YR and was minimum (52.08) in the sample WF and TF. A decrease in the mean values of firmness was seeing during the storage intervals of plum fruit in 32 days show in (Fig. 5). The statistical analysis showed that temperature and storage intervals of treatments had a significant $(\mathrm{P}<0.05)$ effect on firmness content of plum fruit during storage intervals. Firmness loss varied widely among treatments after 14 and 25 days at $10{ }^{\circ} \mathrm{C}$. After 14 days, control and Methyl Jasmonate (MJ) 10-5 M treatedfruit had lost 56-60\% of their initial firmness while MJ 10-4 M fruit had only a $42 \%$ loss of firmness. However, no significant differences were found among control, fruit treated with $\mathrm{MJ}$ and packaged controls, after 4 days at $20{ }^{\circ} \mathrm{C}$. However, after 32 days at $10{ }^{\circ} \mathrm{C}+4$ days at $20^{\circ} \mathrm{C}$, no appreciable differences in firmness were found among treatments, except for control and MJ 10-4 M fruit that showed the lowest firmness values. MJtreatment alone, reduced loss of firmness, but when combined with modified atmosphere packaging (MAP), a further reduction in firmness loss was observed. Previous studies demonstrated that MJ treatments slightly decreased the firmness of strawberry (Perez et al., 1997) but did not affect the firmness of mango 'Tommy Atkins' during cold storage and shelf life (González-Aguilar et al., 2000). It appears that response of fruit to MJ treatment in the reduction of firmness loss may be related to the cultivars and the MJ concentrations used. 


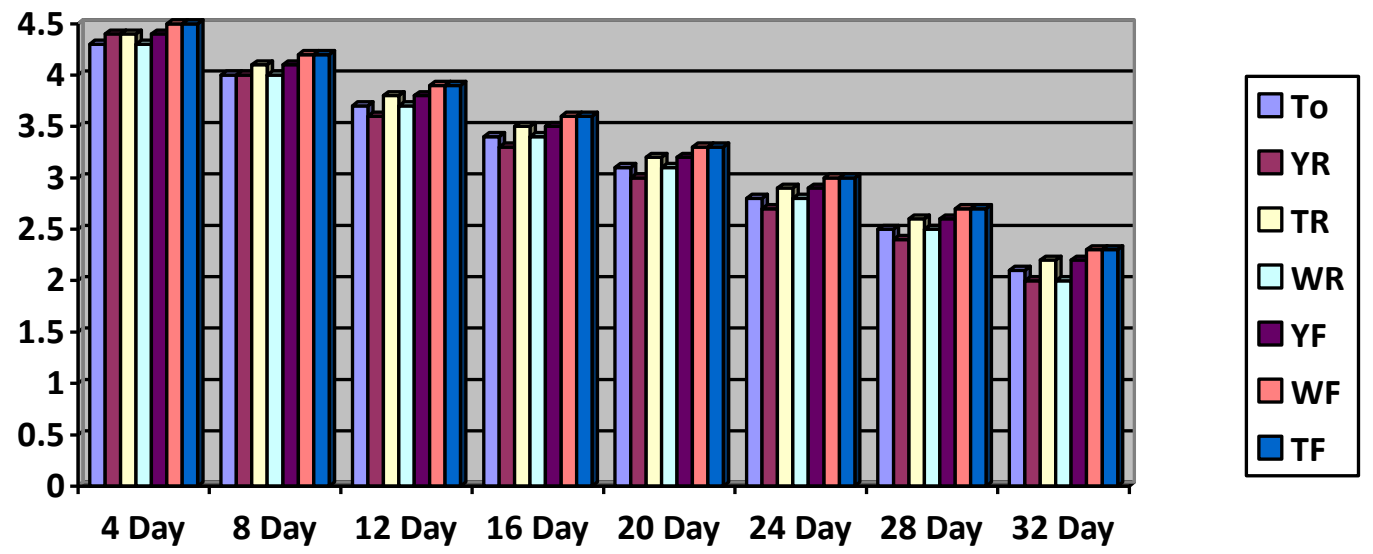

Fig. 5. Effect of different colored polyethylene packaging on firmness $(\mathrm{kg})$ of plum fruit stored at ambient and refrigerated temperatures.

Acidity \%

The mean values of acidity were observed from 0.65 to 0.78 at storage intervals showing the maximum mean value (0.78) at storage intervals for 32 days for the samples $T_{0}$ was recorded and the minimum mean value at storage intervals for the samples TF was recorded as $(0.65)$ during 32 days of storage period. The percent decrease was maximum (50.51) in the sample TF and was minimum (34.09) in the sample YF. A decrease in the mean values of acidity was seeing during the storage intervals of plum fruit in 32 days show in (Fig. 6). The statistical analysis showed that temperature and storage intervals of treatments had a significant $(\mathrm{P}<0.05)$ effect on acidity content of plum fruit during storage intervals. The possible reason for the variation ma be due to the difference in the micro environment created by coatings, packaging and ethylene absorbent used, coupled with less oxidative reactions and lesser decline in degradation of acids thus maintaining the integrity of ells. These results are in lines with finding of several researchers (Raje et al., 1997; Li and Yu, 2001; Dong et al., 2004) which were of the opinion that titratible acidity was higher in fruits like Alphanso mango, apple, peaches etc. either treated with coatings or ethylene absorbent as compared to control with similar decreasing trend of acidity stored at ambient temperature. Another possibility for the decrease in acidity is consumption of acid by micro-organisms as a source of carbon. High amount of acidity in treated fruit might be due to the facts that $\mathrm{Co}_{2}$ accumulates internally in the fruit tissues caused acidosis after dissolving and farming carbonic acids. These results were also in line with those of Carrillo et al. (1995).

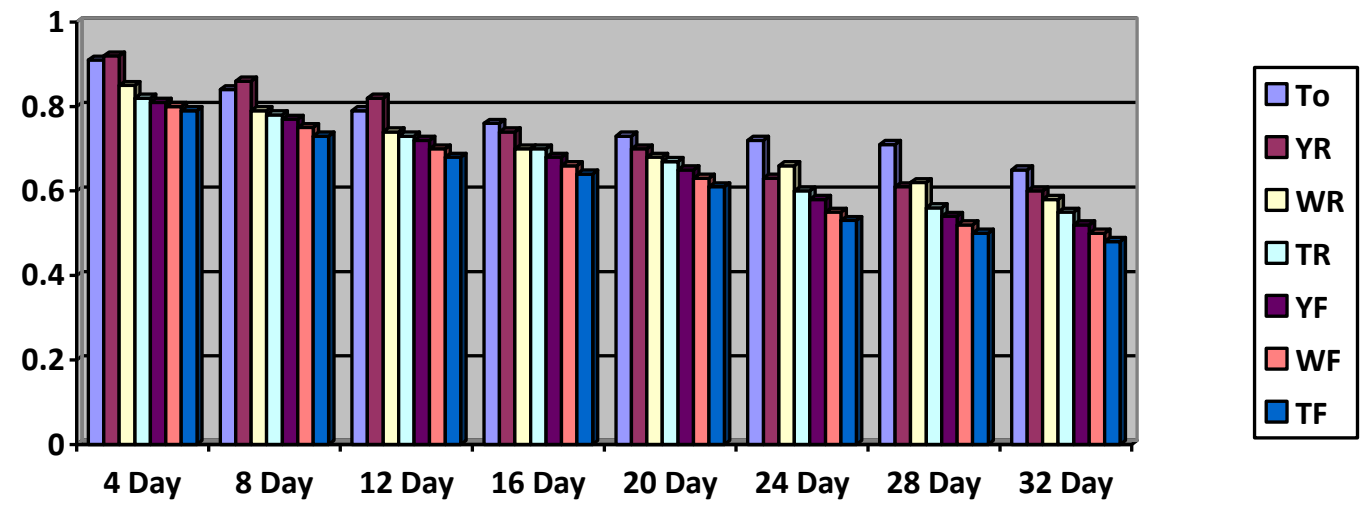

Fig. 6. Effect of different colored polyethylene packaging on acidity (\%) of plum fruit stored at ambient and refrigerated temperatures.

\section{Overall Acceptability}

The mean values of overall acceptability were recorded from 5.67 to 7.03 showing the maximum mean value (7.03) was recorded for the sample TF and minimum mean value (5.67) was recorded for the To. The percent decrease was maximum (75.00) in the sample YR and was minimum (43.52) in the sample TF. A decrease in the mean values of overall acceptability was seeing during the storage intervals of plum fruit in 32 days show in (Fig. 7). The statistical analysis showed that temperature and storage intervals of treatments had a 
significant $(\mathrm{P}<0.05)$ effect on overall acceptability content of plum fruit during storage intervals. These results are in agreement with the findings of Rosario (1996), who observed that increasing storage time cause progressive degradation, which leads to decrease in overall acceptability. However Ca treated fruits rated superior in appearance, aroma, flavor and texture after harvest but the overall acceptance of the $\mathrm{Ca}$ treated fruit continued to be greater than the control fruit even after four weeks of storage. Which are also according to the results of Robson et al. (1989). Acceptability of control fruit rapidly diminished during storage followed by the MJ 10-4 M treatment, while MJ (Methyl jasmonate) $10-5 \mathrm{M}$ retained good visual appearance longer. MAP alone maintained an acceptable appearance equal to the $10-5 \mathrm{M} \mathrm{MJ}$ treatment, after 14 days at $10^{\circ} \mathrm{C}+$ shelf life, but the appearance of the packaged control samples declined to below the acceptable level after 25 days at $10^{\circ} \mathrm{C}+4$ days at $20^{\circ} \mathrm{C}$. No significant differences were found among packaged control fruit and those treated with MJ $10-5 \mathrm{M}$, after 32 days at $10^{\circ} \mathrm{C}+4$ days at $20^{\circ} \mathrm{C}$. Papaya fruit treated with $10-4$ or $10-5 \mathrm{M}$ MJ plus MAP maintained the best visual appearance (rating, very good) after 32 days at $10^{\circ} \mathrm{C}+4$ days at $20^{\circ} \mathrm{C}$. However, no significant differences were found among the MJ treatments when combined with MAP, at the end of the storage period (González-Aguilar et al. 2001).

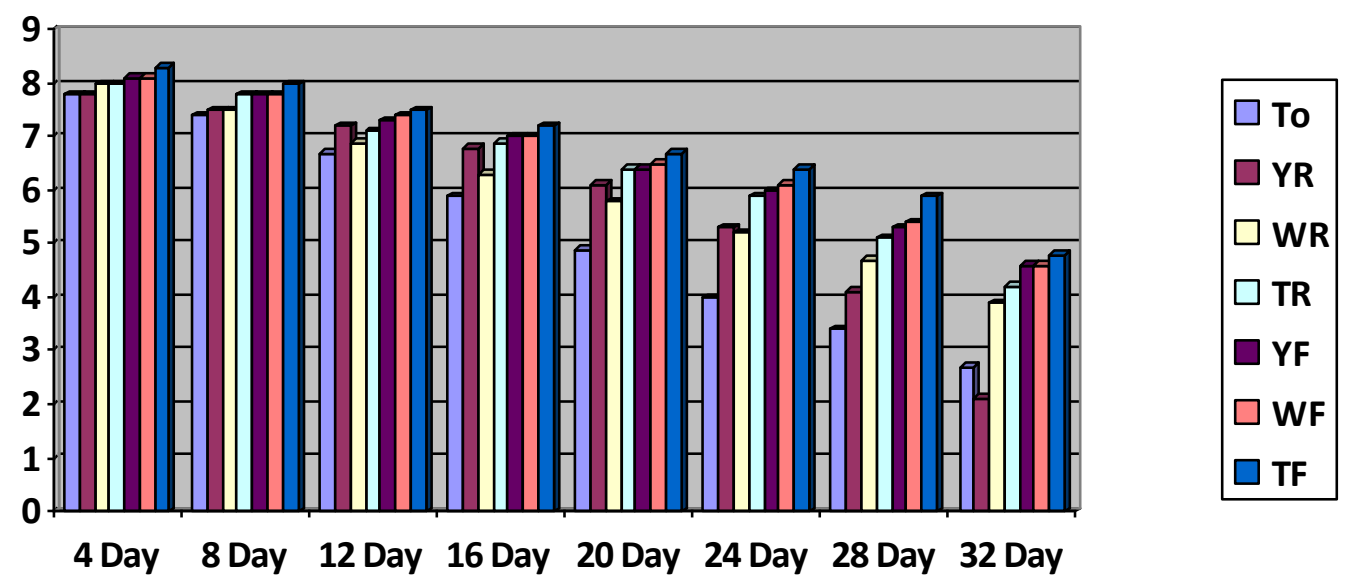

Fig. 7. Effect of different colored polyethylene packaging on overall acceptability parameter of plum fruit stored at ambient and refrigerated temperatures.

\section{Conclusion}

Our results show that yellow and white polyethylene packaging were found less effective than transparent polyethylene packaging for extending storage life of plum fruit with transparent polyethylene packaging retained maximum firmness, TSS, ascorbic acid content, color, flavor, texture, overall acceptability, and reduced decay index and weight loss as compared to other colored packaging.

\section{References}

[1]. A.O.A.C (Association of official Analytical Chemists). 2000. Official methods of analysis, 15th edition, (Ed. Helrich, K.) Arlington, Virginia USA. 513

[2]. Ahmed, D.M., O.M. Hafez and M.D. Solliman. 2007. Integrated control of post harvest decay on blood orange fruits by curing, hot water and sodium carbonate applications. J. Agri. Bio. Sci. 3(6): 590-598.

[3]. Carrillo, L.A., J.B. Valdez-Torres, R. Rojas-Villegas, E.M. Yahia and J.A. gomes. 1995. Ripenning and quality of mangoes affected by coating with Semperfresh. Acta. Hort. 370: 203-216.

[4]. Chiesa, L., L. Diaz, O. Cascone, K. Pańak, S. Camperi, D. Frezza and A. Fragaus. 1998b. Texture changes on normal and long shelf life of tomato (Lycopersicon esculentum Mill.) fruit ripening. Acta Hort. (ISHS) $464(1)$ : 487. http://www.actahort.org/books/464/464 81.htm. Updated on 2004 June. Accessed 2004 July 14.

[5]. Dong, H., L. Cheng, J. Tan, K. zheng and Y. Jiang. 2004. Effects of chitosan coating on quality and shelf life of peeled litchi fruit. J. Food. Eng. 64: 355-358.

[6]. Gongnian X, M. Zhang, L. Shan, Y. You and V. M. Salokhe. 2011. Extension of the shelf-life of fresh oyster mushrooms (Pleurotus ostreatus) by modified atmosphere packaging with chemical treatments. State Key Laboratory of Food Science and Technology, Jiangnan University, Wuxi 214122, People's Republic of China. African Journal of Biotechnol. 10(46): 9509-9517.

[7]. Gonzalez-Aguilar. G.A., J. Fortiz, R. Cruz, R. Baez, C.Y. Wang. 2000. Methyl jasmonate reduces chilling injury and maintains postharvest quality of mango fruit. US Department of Agriculture, Produce Quality and Safety Laboratory, Agricultural Research Service. J. Agric. Food Chem. (48): 515-519.

[8]. Greg, J and R. Santi. 1987. Quality of fungicide treated and individually shrink wrapped tomatoes. J. Food Sci. 52(5): 1293-1297.

[9]. Guevara, J.C., Yahia, E.M., Brito de la Fuente, E. and Biserka, S.P. 2003. Effects of elevated concentrations of CO2 in modified atmosphere packaging on the quality of prickly pear cactus stems (Opuntia spp.). Postharv. Biol. Technol. 29: 167-176.

[10]. Hussain, S. 1986. Effect of different packaging material on the overall quality of fruit juices. M.Sc(Hons) Thesis, deptt. Of food Sci. and Tech., Uni. Of Agric., Faisalabad. 48. 
[11]. Khan, I and M. Ahmad. 1987. Effect of waxing and cellophane lining on chemical quality indices of citrus fruit. Plant Foods for Human Nutrition (Formerly Qualitas Plantarum). Vol 37 (1): 47-57.

[12]. Kinh, S. A. E. H., C. P. Dunne and D. G. Hoover. 2001. Preparation and preservation of apple pulp with chemical preservatives and mild heat. J. Food Prot. 28(6): 111-114.

[13]. Larmond, E. 1977. Laboratory method of sensory evaluation of food. Canada Deptt. Agri. Ottawa.

[14]. Li, H and T. Yu. 2001. Effect of chitosan coating on incidence of brown rot, quality and physiological attributes for post harvest peach fruits. J. Sci. Food Agric. 81: 269-274.

[15]. Perez, A.G., C. Sanz, D. G. Richardson, J. M. Olias. 1997. Effect of methyl jamonate on in vitro strawberries ripening. US Department of Agriculture, Produce Quality and Safety Laboratory, Agricultural Research Service. J. Agric. Food Chem. (24): 3733-3737.

[16]. Raje, L., S. Sherlekar, K. Ramakrishnan, V.C. Malshe and G.Subbulakshmi. 1997. Post harvest presaevation of mangos by controlled chemical release agents and adsorbent. Acta Hort. 455: 622-628.

[17]. Robson, M.G., J.A. Hopfinger and P. Eck. 1989. Post harvest sensory evaluation of calcium treated peach fruit. Acta Hort. 254: $173-177$.

[18]. Saima, N. 2001. Quality improvement and shelf life extention of plum fruit. Thesis. Horticulture Department. Khyber Pakhtunkh wa Agricultural University Peshawar.

[19]. Sarkar, H.N., A.M. Hasan and P.K. Chattopadhyay . 1997. Influence on polyethylene packing on the post harvest storage behavior of banana fruit. J. Hort. 10: 31-39.

[20]. Steel, R.G.D and J.H. Torrie. 1997. Principlals and procedure of statistics. McGraw Hill Book Co. New York. Vide: Gomez, K.A and A.A Gomaz (1984) statistical procedure for Agri: res (2 ${ }^{\text {nd }}$ Ed.:8-22.

[21]. Sumnu, G and Bayindirli. 1995. Effect of coatings of fruit quality of amasya apple. Lebensm:wiss.u. Technol. 28: 501 -505.

[22]. Togrul, H and N. Arslan. 2004. Extending shelf life of peach and pear by using corboxy methyl celleluse (CMC) from sugar beet pulp cellulose as hydrophilic polymer in emulsions. Food hydrocolloids. 18: 215-226.

[23]. Wang, Y., S.S.P. Tian and Y. Xiu. 2005. Effect of high oxygen concentration on anti oxidant enzymes in peach fruits during post harvest periods. J. Food Chem.91: 99-104.

[24]. Xiao, G.N and M. Zhang. 2003. Study of respiration regulation of Pinggu mushroom and strawberry under modified atmosphere packaging. J. Wuxi. Univ. Light Ind. 4: 115-123.

[25]. Zhang, M., D.J. Baerdemaeker, E.Schrevens. 2003. Effects of different varieties and shelf storage conditions of chicory on deteriorative color changes using digital image processing and analysis. Food Res. Int., 36: 669-676. 